\title{
aEEG AS A POOR BRAIN PERFUSION DETECTOR IN PRETERM INFANTS
}

\author{
AC. Borrelli A. Casani F. Cocca L. Ferrante G. Di Manso L. Grappone N. Pozzi, A. Scoppa \\ NICU - San Pio Hospital - Benevento - ITALY
}

\section{Background and Aims}

The implementation of Amplitude-Integrated electroencephalography (aEEG) has enhanced the neurological monitoring of critically ill infants. The aim of the study is to observe if aEEG monitoring is a valid detecting tool for brain perfusion in preterm infants

\section{Method}

35 preterm infant with a gestational age between 24 to 32 weeks were monitored with aEEG during their first 7 days of life. For investigation we used the C3-C4, P3-P4 electrode positioning of international 10-20 system. The background pattern was assessed according to Burdjalov score (Fig 1). Six patient died in first 7 days end was excluded from the study.

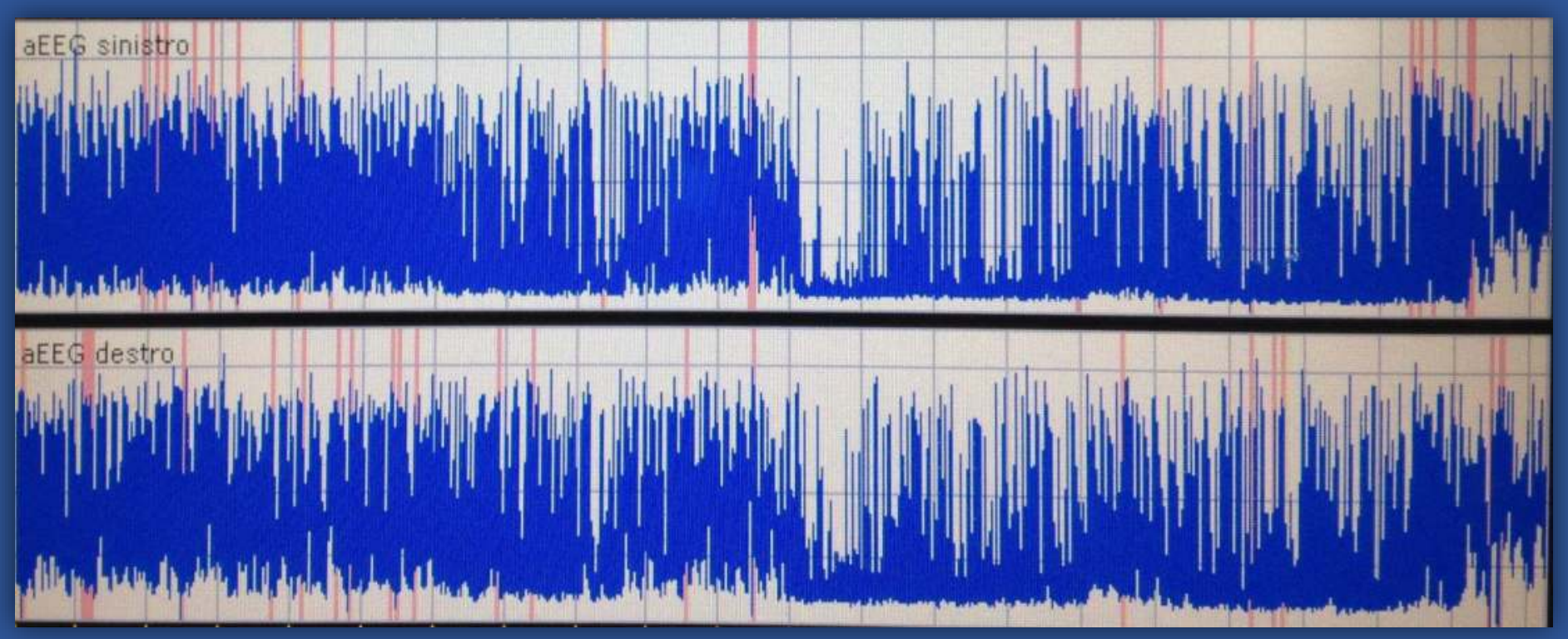

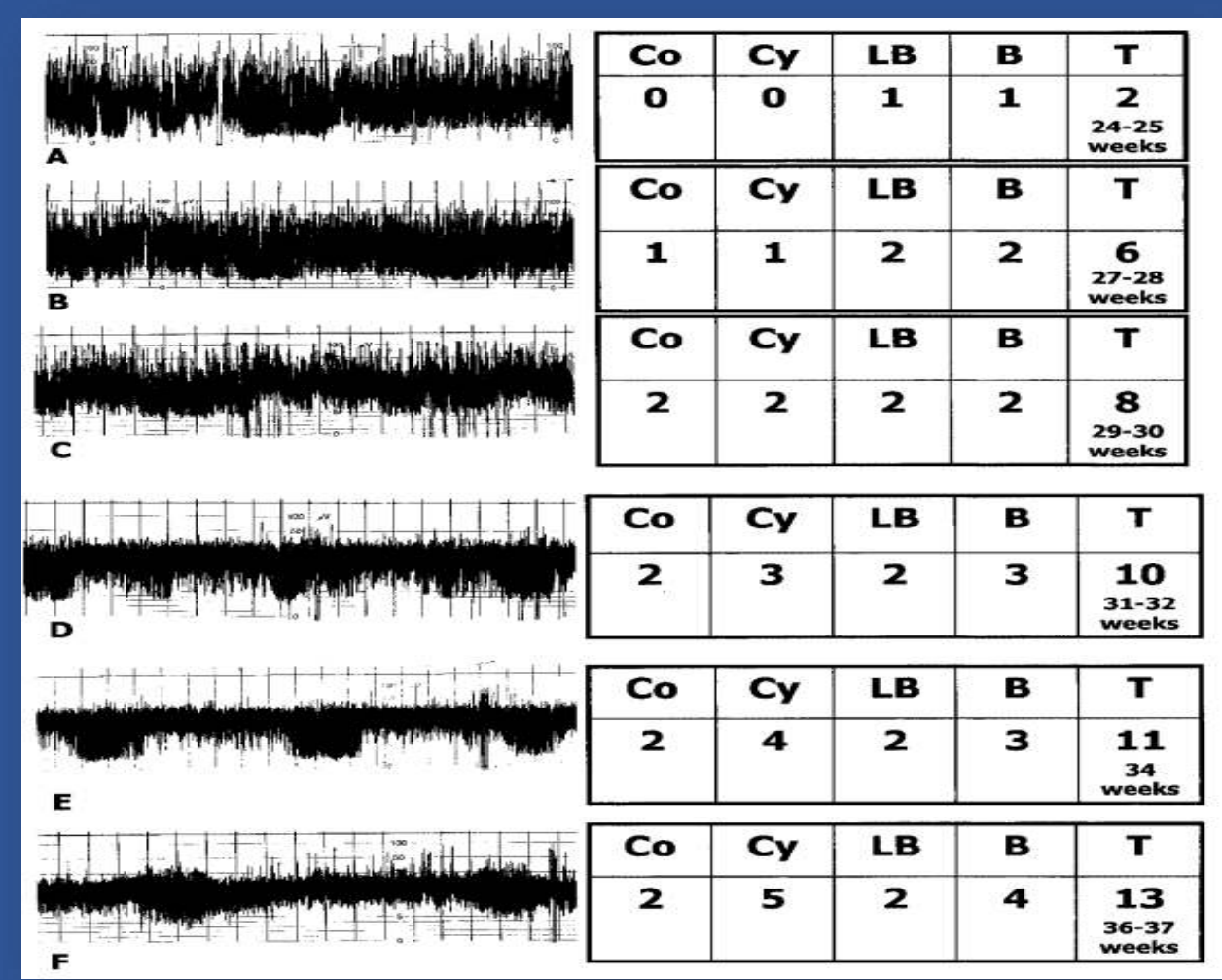

Fig 1

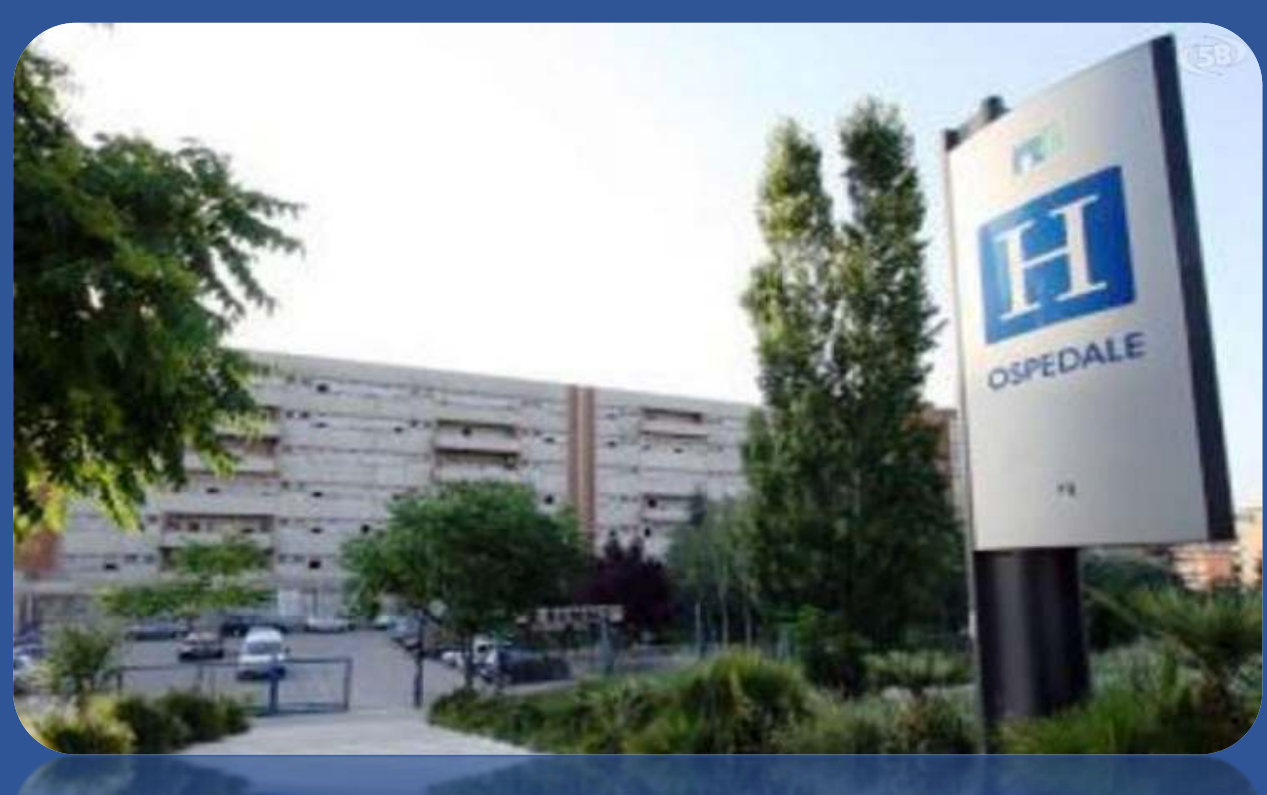

Fig 2

\section{Results}

$5(14 \%)$ infants showed a low Burdjalov score in first 48 hours of life because of intraventricular and intraparenchymal haemorrhages. Whereas $4(11 \%)$ preterm babies showed a tardive sudden worsening of the score (fig 2). These 4 patient in the following hours showed tachycardia, signs of hypoperfusion, 2 of them showed arterial hypotension. We observed normal aEEG Burdialov score in the remaining patients. Therefore aEEG monitoring in the first 7 days of life showed a high positive predictive value (PPV 100\%) for brain poor perfusion.

\section{Conclusion}

Poor brain perfusion is not uncommon in preterm babies is with very low birth weight. Amplitude Integrated Electroencephalography may help to evaluate changes in their electrical activity. Our results suggests that aEEG is a valid detecting tool for very early detection brain poor perfusion.

\section{References}

1) de Vries LS, Hellstrom-Westas L. Role of cerebral function monitoring in the newborn;Arch Dis 1) de Vries LS, Helstrom-Westas: Role of
Child Fetal Neonatol eD 2005;90:F201-207

2) Shah DK, de Vries LS, Hellstrom-Westas L,Toet MC, Inder TE; Amplitude-integrated Elettroencephalography in the Newborn: A Valuable Tool;Pediatrics;122:863-865

3) Wikstrom S, Pupp IH, Rosen I, Norman E, Fellman V, Ley D, Hellstrom-Westas L. Early singlechannel aEEG/EEG predicts outcome in very preterm Infants. Acta Paediatr, 2012 Jul;101(7):719726

4) Olischar M, Klebermass $K$, Waldhoer T, Pollak A, Weninger M; Background Patterns and sleepwake cycles on amplitude-integrated elettroencephalography in preterms younger than 30 weeks gestational age with peri-/intraventricular Haemorrhage; Acta Paediatr 2007, Dec; 96(12)1743-50

5 )Burdjalov VF, Bumgart S, Spitzer A; Cerebral Function Monitoring: a New Scooring System for the Evaluation of Brain Maturation in Neonates; Padiatrics 2003;112:855-861

6) Olischar M, Klebermass K, Kuhle S, Hulek M, Kohlhauser C, Rucklinger E, Pollak A, Weninger M: Reference Values for Amplitude- Integrated Electroencephalographic Activity in Pretrm Infant Younger 30 Weeks' Gestational Age; Pediatrics 2004;113:e61e65 